\title{
Feeding Behavior, Milking Behavior, and Milk Yields of Cows Milked in a Parlor Versus an Automatic Milking System
}

\author{
A. M. Wagner-Storch and R. W. Palmer \\ Department of Dairy Science \\ University of Wisconsin, \\ Madison WI 53706
}

\section{ABSTRACT}

This study compared feeding and milking behavior and milk yields for cows housed in the same barn, fed the same ration, but milked with a conventional milking parlor (parlor) or automatic milking system (robot). Behavioral data were videotaped hourly $1 \mathrm{~d} / \mathrm{mo}$ for 9 mo. Feeding behavior patterns differed and were more variable for parlor cows than for robot cows. Both groups had low feeding rates at night and early morning. Feeding activity increased after milking and feed delivery for parlor cows. Milking and feeding activity in the robot system increased after human intervention at 7 a.m.; feed bunk activity peaked $3 \mathrm{~h}$ later and remained relatively constant from 10 a.m. to 8 p.m. Percentages of cows at the feed bunk were significantly greater for robot cows than parlor cows only at 10 a.m. and 9 p.m. Batch milking of parlor cows with free access to feed, vs. sequential milking of robot cows, with restricted movement to feed by a one-way gate system, resulted in higher peak percentages of cows at the bunk for parlor cows. Lower, more consistent percentages of cows eating at one time suggests that less bunk space may be needed for cows in robotic milking systems. Higher percentages of cows were observed in the robot from 8 a.m. to 1 p.m. and again from 3 to 7 p.m. Percentages of cows in the robot holding area were greatest from 8 to $11 \mathrm{a} . \mathrm{m}$. and 3 to $6 \mathrm{p} . \mathrm{m}$. and were lowest from midnight to 6 a.m. Milk production over $39 \mathrm{~d}$ in summer for subsets of cows was slightly but significantly higher ( 26.4 vs. $25.8 \pm 0.2 \mathrm{~kg} / \mathrm{d}$ ) for cows in the robot group. Milking frequency, days in milk, parity, and maximum air temperature for $3 \mathrm{~d}$ (-2 d to day of observation) affected milk yield comparisons. Results have implications for design of feeding and handling facilities used with automated milking systems.

(Key words: cow behavior, automatic milking system, feeding behavior, milk yield)

Received May 14, 2002.

Accepted September 26, 2002

Corresponding author: R. W. Palmer; e-mail: rwpalmer@facstaff. wisc.edu.
Abbreviation key: parlor $=$ double -6 herringbone parlor; robot $=$ automated milking system

\section{INTRODUCTION}

Conventional parlor milking systems (parlor) provide a more structured daily routine, whereas automatic milking systems (robot) allow for more flexibility in milking times for individual cows. Different milking systems can affect daily activity. Monitoring cow activity can lead to a better understanding of cow behavior, scheduling of routine activities, and potentially lead to improvements in design of facilities for efficient management.

Initial reports with automatic milking systems indicate that cow feeding and milking activity is more evenly distributed across a 24 -h period. However, visits to a robotic milker are lower during the night and early morning hours (Wendl et al., 2000; Olofsson et al., 2000). Wendl et al. (2000) found that the highest number of milking visits to the robotic milker were in the morning. Olofsson et al. (2000) reported that feed intakes were lower during the night for cows in an automatic milking system. O'Connell et al. (1993) reviewed a study which found increased cow feeding activity occurred during the day and early evening hours (9 a.m. to 3 p.m. and 5 p.m. to 1 a.m.) vs. late night and early morning ( 1 a.m. to 7 a.m.), when cows were studied in confinement. The type of milking system used was not described but likely was not an automatic system.

Association with an opportunity to eat may motivate cows to visit robotic milking machines more frequently. A one-way gate system forces a cow to pass through a robotic milking unit to get to the feed bunk. Approximately 30 to $56 \%$ of total visits to a robotic milker were nonmilking visits, with the highest frequency occurring in the afternoon (Wendl et al., 2000; Morita et al., 2000). Therefore, cows do apparently visit the robot in order to reach the feed bunk.

An issue that has not been addressed in previous studies with automated milking systems is cow behavior and milk response during hot weather. Maintaining milk yield in dairy cattle is essential for a dairy farm's 
profitability during periods of thermal stress. Monitoring changes in milk yield is important to ensure production levels are maintained. Cow characteristics, such as DIM and parity; management practices such as use of bST and frequency of milking; and weather conditions, such as temperature and relative humidity, influence milk yield.

Previous studies have examined effects of thermal stress on milk yield. Maximum, minimum, mean temperatures, relative humidity, and calculated temperature humidity indices have been evaluated as variables representing heat stress. Ravagnolo and Misztal (2000) and Maust et al. (1972) found maximum temperature to be a good measure of the weather's effect on milk yield. High temperatures and temperature humidity index values $(>72)$ negatively affected production performance (Linvill and Pardue, 1992; Armstrong, 1994; West, 1994; Ravagnolo and Misztal, 2000). Previous days' weather conditions have been considered as a possible factor affecting test day yields by Ravagnolo and Misztal (2000). Maust et al. (1972) found weather conditions 2,3 , and $4 \mathrm{~d}$ previous to be significantly correlated with a current milk yield.

Milking frequency can also directly affect milk yield and is a significant variable in predicting yields (Ravagnolo and Misztal, 2000). Research has focused on the yield response of two times per day milking vs. three times per day, as well as differences between parity groups. A review of published studies found a relatively fixed milk yield response of $7.7 \mathrm{lb} / \mathrm{d}(3.5 \mathrm{~kg})$, by increasing milking frequency from two to three milkings per day for both primiparous and multiparous cows (Erdman and Varner, 1995). Effects of milking frequency and parity on yield response of selected (AI sires) vs. nonselected cows were reported by Barnes et al. (1990). Their results showed an increase in second parity yield with three-times-a-day milking over first parity yield in both genetic groups.

The objectives of the current study were to: 1) compare feeding behavior of cows milked in a conventional milking parlor (parlor) with those in an automatic milking (robot) system; 2) monitor cow milking behavior for a robotic milking system; 3 ) determine the effect on milk yield of cows milked with a conventional herringbone milking parlor $2 \times$ and cows milked in a robotic milking system; and 4) determine effects of ambient temperature during hot weather on daily milk yields within the two milking systems.

\section{MATERIALS AND METHODS}

The study was conducted in the University of Wisconsin-Madison Agricultural Research Station free-stall barn located in Arlington, Wisconsin. It is a 4-row, 104 stall, tail-to-tail barn that uses natural ventilation and is not insulated. The barn is oriented east to west and has dimensions of $100 \mathrm{ft}$ wide $\times 120 \mathrm{ft}$ long $(30.5 \times 36.6$ m) and a roof pitch of 4/12. It has a woodpost-frame structure, with 6 in $\times 6$ in $(15.2 \times 15.2 \mathrm{~cm})$ wood posts located at the feed bunk line and at the front of the internal row of stalls. Eave sidewall height is $12 \mathrm{ft}$ ( 3.66 $\mathrm{m})$. Ventilation is controlled by a 6.5 in $(16.5 \mathrm{~cm})$ fixed eave opening and $9 \mathrm{ft}(2.75 \mathrm{~m})$ adjustable side curtains. The ridge opening is 24 in $(61 \mathrm{~cm})$. No fans or sprinklers are used. Stocking densities were approximately $100 \%$ on the south side and $66 \%$ on the north side. Research protocols insured animal care guideline compliance.

\section{Video Monitoring Equipment}

Four HOBO (Onset Computer Corporation, Pocasset, MA) H8 Pro Series sensors recorded temperature every $15 \mathrm{~min}$. One sensor was located in each quadrant of the barn, northwest (NW), northeast (NE), southwest (SW), southeast (SE). Sensors were 38 to $40 \mathrm{ft}$ (12.6 to 13.2 $\mathrm{m})$ from each end wall, and 9 to $10 \mathrm{ft}$ (2.9 to $3.3 \mathrm{~m})$ above the alley floor surface over the front of the interior row of stalls. Data were downloaded from the sensors via a HOBO Shuttle. Videotape images were observed once per hour, as close to the beginning of the hour as the camera sequence would allow, on the 15th of each month from May 2001 to January 2002.

\section{Animal Grouping}

The south side of the barn housed cows milked in a conventional double- 6 herringbone parlor, and the northside-housed cows milked with a Bou-matic (Boumatic Dairy Equipment Company, Madison, WI) robot. Barn characteristics and videotape observation methods are described in more detail by Wagner-Storch et al. (2002). Briefly, the robot pen was equipped with a series of one-way gates, which only allowed cows to access the feed alley through the robot. The robot maintained a 10-d rolling average hourly milk level for each cow and used it to estimate the amount of milk expected from the cow based on the length of time since she was last milked. If expected milk was greater than the milk threshold level of $13.2 \mathrm{lb}$ ( $6 \mathrm{~kg}$ ), the cow was milked, if not she was released to the feed bunk area. The robot and adjacent holding area were visible $24 \mathrm{~h}$ per day because the area near the robot was lighted. The status of the robot, in-use (cow being milked) or not in use, and the number of cows in the robot holding area were recorded. A cow was assumed to be in the robot holding area if she was past the northeast waterer or if held in the gated area near the robot.

During the 9-mo study period, the number of cows milked in the parlor ranged from 43 to 58 cows, with 
a mean of 52 cows, and the number of cows milked by the robot ranged from 30 to 43 cows, with a mean of 36 cows.

\section{Feed Bunk Monitoring}

The number of cows at the feed bunk was recorded for both sides of the barn. A cow was counted as "at the feed bunk" if her head was through a self-locking manger stall (self-locks) opening. Wooden support posts blocked the view of approximately $2 \mathrm{ft}(0.6 \mathrm{~m})$ of the feed bunk on both sides of the barn. Both groups of cows were fed once daily (at approximately 11:00 a.m.), and cows were fed enough to support an $8 \%$ feed refusal.

Scheduled milking (6:00 a.m. and 5:00 p.m) and feeding (11:00 a.m.) times were set for cows milked in the parlor, but actual times varied. For cows milked by the robot, there were a scheduled wash cycle (2:00 p.m.) of the robot and a daily scheduled human-intervention time (7:00 a.m.) that influenced cow behavior. Humanintervention time refers to the scheduled time of day when an employee would identify cows not milked in the previous $15 \mathrm{~h}$ or cows that did not routinely visit the robot without human-intervention. These cows were manually guided to the holding area in front of the robot.

Long-day lighting in the barn prevented accurate collection of feed-bunk data during the scheduled dark period, 9:30 p.m. to 3:30 a.m., and feeding behavior data from those times are not included. Feed-bunk data were summarized as an average percentage of total cows at the feed bunk, by management group, for each hour, with calculated standard errors of those percentages. (Example calculation for average percentage of total cows at the south side (parlor) feed bunk at 2 p.m. for 9 d over 9 mo.: $[(5 / 43)+(8 / 48)+(5 / 54)+(6 / 54)+(7 /$ $53)+(6 / 54)+(29 / 52)+(9 / 53)+(12 / 52)] / 9=0.188 \times$ $100=18.8 \pm 4.8 \%)$. The status of the robot and number of cows in the robot holding area were summarized as average hourly percentages \pm standard errors. A paired $t$-test (SAS, 1999) was run to compare feed bunk percentages at each hour from 4 a.m. to 9 p.m. for each management group. A transformation, arcsine (square root [average proportion]) was done to account for unequal variances. Data from 12 a.m. to 3 a.m. and from 10 p.m. to 11 p.m. were not tested due to insufficient observations.

\section{Milk Yield Model}

Temperature, milk yield, and cow characteristic data were collected from July 9 to August 16, 2001. This period, during the hot summer conditions, was specifically selected to study the effect of parity, DIM, milking frequency (parlor $=2 \times$, robot $=1 \times$ to $4 \times$ ), and high temperatures on daily milk yields.

Temperature data used in the analysis were maximum value per day for each side of the barn. The maximum daily temperature for cows on the parlor side of the barn was determined from the higher of SW and SE sensors, and the maximum daily temperature for cows on the robot side was determined from the higher of NW and NE sensors.

Cow milk yield, parity, DIM, and milking frequency were collected from electronic records. Records were removed from the analysis if determined not to be plausible: milking frequency unequal to 2 on the parlor side, greater than 4 on the robot side or milk yield less than $10 \mathrm{lb}(4.54 \mathrm{~kg})$.

Data from 122 different cows were used in the analysis. Six cows had records for both sides of the barn, because they were moved from one side to the other during the study. Therefore, data from 84 cows in the parlor group and 44 cows in the robot group were available. Total number of cow-day observations in the analysis was 2982.

Daily milk yield data were analyzed with the MIXED Procedure in Statistical Analysis Software (SAS, 1999). The following model was tested: $\mathrm{y}_{\mathrm{hijk}}=\mathrm{c}_{\mathrm{h}},+\mathrm{mf}_{\mathrm{i}}+\mathrm{p}_{\mathrm{j}}+$

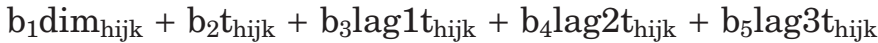
$+\mathrm{e}_{\mathrm{hijk}}$ where $\mathrm{y}_{\text {hijk }}$ is daily milk yield for cow $\mathrm{h}$ with milking frequency $i$, parity $j$, on day of lactation $\mathrm{k}$. Continuous variables were days in milk (dim), maximum temperature on observation day ( $\mathrm{t}$ ), maximum temperature from one day previous (lag1t), maximum temperature from $2 \mathrm{~d}$ previous (lag2t), maximum temperature from three days previous (lag3t), and residual. A repeated statement, type $=\mathrm{AR}(1)$, was used to account for autocorrelation errors due to repeated measures on each cow (Littell et al., 1998). Milking frequency, parity, and cow were categorical variables. The main objective of this research was to measure robot and parlor differences. However, it should be noted that due to physical constraints of the facility, the side of the barn was confounded with milking frequency and milking system, and therefore not included in the model. Replication of barns with robot and parlor milking systems on both sides was not possible. The average temperature on the south side (parlor) was almost $0.5^{\circ} \mathrm{F}\left(0.28^{\circ} \mathrm{C}\right)$ warmer in the summer and over $1.0^{\circ} \mathrm{F}\left(0.56^{\circ} \mathrm{C}\right)$ warmer in the winter than on the north side (robot). This was not accounted for in the milk yield model and may have biased the results shown.

During July, 50\% (parlor) and 57\% (robot) of the cows received bST treatments. In August, $48 \%$ (parlor) and $52 \%$ (robot) of the cows received bST treatments. However, bST use was similar in both groups and variation 




Figure 1. Feed bunk activity - Average percentage of total cows at the feed bunk on the 15th of each month for 9 mo for cows on the parlor side and cows on the robot side for each hour, where: "M" represents the scheduled milking times (6 a.m. and 5 p.m.) for cows milked in the parlor, "F" represents scheduled feeding time (11 a.m.), "W" represents scheduled wash cycle of the robot (2 p.m.), and "H" represents scheduled human-intervention time (7 a.m.) for the cows milked by the robot to ensure that all cows get milked.

from bST use was included in the calculated residual value, making significance tests more conservative.

Models testing maximum and mean temperature effects separately, and maximum and mean temperatures together, were analyzed for the observation day, and 1,2 , and $3 \mathrm{~d}$ previous to that day.

\section{RESULTS AND DISCUSSION}

\section{Feed Bunk Activity}

Results for observed feeding behavior at the feed bunk are summarized in Figure 1. The highest numeric average percentages of cows at the feed bunk within the parlor group were observed at 7 a.m., 1 p.m., 3 p.m., 6 p.m, and 7 p.m. (21.5, 21.0, 22.5, 27.5, and $25.1 \%$ respectively; Figure 1). Those high points closely followed the scheduled milking times and near the scheduled feeding time between the a.m. and p.m. milkings. Those percentages are lower than expected because actual milking times varied from scheduled times. A summary of one day's data, taken at 15-min intervals, showed the following average percentage of cows at the feed bunk over a 2 -h period, starting when cows left their pen to be milked: $0,0,0,28,55,57,42$, and $31 \%$. Summarizing at a fixed time and having days with delayed milking reduced average percentages of animals at the bunk to the values shown in Figure 1. Average percentages of cows at the feed bunk were less than
$10 \%$ in the evening and early morning hours $(9$ p.m. to 6 a.m.). Cows had greater feeding activity during the day than during the night and early morning. A similar pattern was reported previously (O'Connell et al., 1993). Using a paired $t$-test to compare feed bunk percentages at each hour from 4 a.m. to 9 p.m. for each management group, percentages differed $(P<0.05)$ at several times. Each hour before scheduled milkings and before scheduled feeding were all different than $2 \mathrm{~h}$ after the associated scheduled activity for the parlor cows. High variability was associated with the percentages the hour after either milking or feeding which prevented the hour immediately after milking or feeding from being significant. This was assumed to be caused by the variation in actual milking or feeding times vs. scheduled times. Percentages of cows at the feed bunk early in the morning (4 to 6 a.m.) were lower than at the midday (12 to 4 p.m.)

Average percentages of total cows at feed bunk for the robot group were less than $10 \%$ from 10 p.m. to 7 a.m., then gradually increased to a peak of $19.5 \%$ at 10 a.m. Activity at the bunk remained relatively high until 2 p.m., declined until 6 p.m., and then reached another peak level at 7 p.m. (20\%) and 8 p.m. (19\%). The first high point was $3 \mathrm{~h}$ after the scheduled human-intervention time. This human-intervention period was associated with a large number of animals waiting in the robot holding area. As these animals were milked, they gradually moved to the feed alley. The milking speed 
of the robot and the amount of time cows remained at the feed alley determined the number of cows at the feed alley. All cows in this experiment had been conditioned to $2 \times$ milking in a conventional parlor before entering this trial. The second high frequency of cows at the feed bunk may have been caused by animals voluntarily being milked a second time. This may have been initiated by a number of reasons including their desire to be milked again (udder pressure), desire for more feed, or a conditioned response from a previous $2 \times$ milking schedule.

The paired- $t$ test on the robot side showed feeding percentages early in the morning (4 to 6 a.m.) were lower $(\mathrm{P}<0.05)$ than after the 7 a.m. scheduled humanintervention time. Few differences were found during the day and early evening ( 7 a.m. to 9 p.m.), except the highest numerical percentage (10 a.m.) was higher than late afternoon (5 to $6 \mathrm{p} . \mathrm{m}$.), before the percentage of cows at the feed bunk increased again. The percentage of cows at the feed bunk at 9 a.m. was less than that at 10 a.m., which shows the cow numbers at the bunk continued to rise to a peak about $3 \mathrm{~h}$ after humanintervention and again from 7 to 9 p.m., after which feeding activity decreased. The 7 a.m. percentage was different from 10 a.m. and 12 p.m., when feed bunk activity was high. It appears that cows started going through the robot after the human-intervention time, causing the cow numbers to increase at the feed bunk until about 10 a.m., remained relatively constant until 5 p.m., and then rose again as cows came to the robot to be milked a second time. No difference was found in feeding behavior associated with the scheduled wash cycle of the robot or the scheduled feeding time for cows in the robot group.

The only significant differences $(P<0.05)$ between the parlor and robot groups in percentages of cows in the feeding area were at $10 \mathrm{a} . \mathrm{m}$. and 9 p.m. At 10 a.m., the average percentage of total cows at the feed bunk in the robot group increased to approximately $20 \%$ after the cow build-up, which was initiated by the earlier human-intervention time. The average percentage of total cows at the parlor feed bunk decreased because cows had eaten after being milked and were lying down. At 9 p.m., cows in the robot group were returning to the feed bunk after being milked, whereas cows on the parlor side had been milked at 5 p.m., had eaten, and again were lying down.

Variability in feed bunk activity for the parlor group increased the hour after the scheduled milking, as indicated by the standard error bars. There was less variability on the robot side than on the parlor side because the parlor cows had a less structured movement and activity schedule.

\section{Activity Within the Automatic Milking System}

The percentage \pm S.E. of total cows in the robot or robot holding area by hour are summarized in Figure 2. The robot was used extensively from 7 a.m. to 7 p.m. with the average number of cows in the robot ranging from approximately 0.5 to 1.0 cows or about $2 \%$ of the group. A smaller average percentage of total cows were observed in the robot during the evening, night and early morning, ranging from approximately 0 to $<2 \%$ from 8 p.m. to 6 a.m. A paired $t$-test was run to compare average percentage of cows in the robot at each hour of the day for the robot management group. No cows were observed in the robot at the 5 a.m. time, so the robot's 5 a.m. average usage was different from all other times. Activity at 12 a.m. was less than the two high activity times of 8 a.m. to 1 p.m. and 4 to 7 p.m. $(P<$ $0.05)$ and less than 3 p.m. $(P<0.10)$. Activity increased at 1 a.m. with a greater average percentage than 3 and 5 a.m. and lower than 10 a.m. The 2 a.m. observation showed greater activity than at 5 a.m. and lower activity than at 8 a.m., 10 a.m., and 7 p.m. The 3 a.m. average was lower than 7 a.m. to 10 p.m. The 4 a.m. average was lower than 8 a.m. to 12 p.m. and 7 p.m. The decrease in activity at the scheduled 2 p.m. wash time was only different from the robot usage at 7 p.m. Based on these results it appears the highest robot activity was from 8 a.m. to 1 p.m. and 3 to 7 p.m. The first period was initiated by and followed human intervention and the second about $8 \mathrm{~h}$ later when many of the cows entered the robot a second time. Activity increased again, but to a lesser degree, at 1 to 2 a.m. and was assumed to be associated with cows being milked a third time.

The number of cows in the robot averaged about one from 8 a.m. to 7 p.m. It was smaller during the evening, night and early morning hours, which is consistent with previous studies (Wendl et al., 2000; Olofsson et al., 2000).

Average percentage of cows in the robot holding area was greatest from 8 to 11 a.m. at about $12 \%$ and 2 to 7 p.m. with approximately 9 to $11 \%$ of the cows waiting to use the robot. The average percentage of cows in the robot holding area was smaller in the evening, night, and early morning, ranging from approximately 1 to $3 \%$ of the cows. A paired t-test was run to compare average percentage of cows in the robot holding area at each hour of the day for the robot management group. The 12 a.m. average was lower than the 7 a.m. to 7 p.m. averages $(P<0.05)$. The 1 a.m. average was lower than the 7 a.m. to 3 p.m and 6 to 7 p.m. averages, but not different from 4 and 5 p.m. because of their large variation. The 2 and 3 a.m. averages were lower than the 7 a.m. to 7 p.m. averages. The 4 a.m. average was lower than the 8 a.m., 11 a.m., and 2 to 6 p.m. averages. 


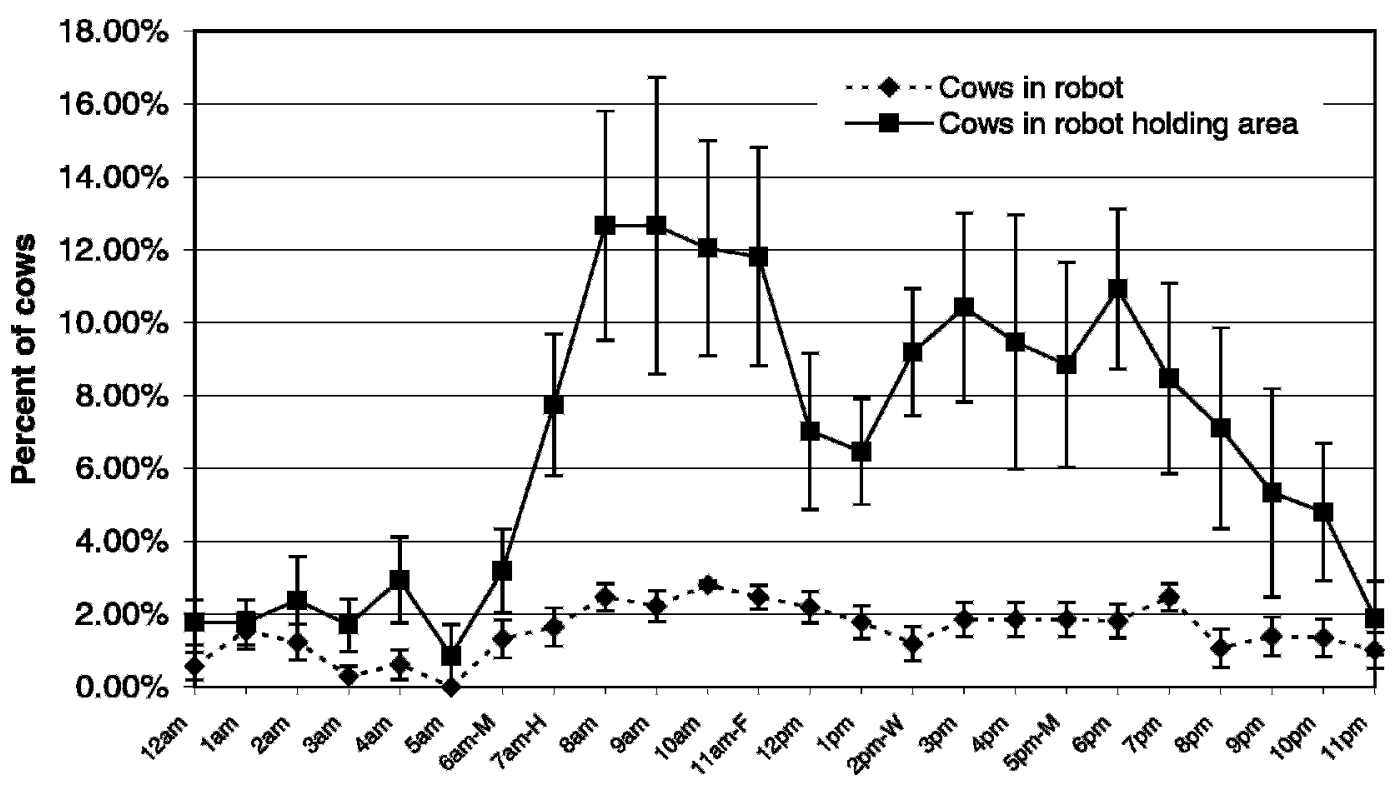

Figure 2. Automatic milking system activity - Average percentage of total cows in the robot and cows in the robot holding area on the 15th of each month for nine months for each hour, where: "M" represents the scheduled milking times (6 a.m. \& 5 p.m.) for cows milked in the parlor, "F" represents scheduled feeding time (11 a.m.), "W" represents scheduled wash cycle of the robot (2 p.m.), and "H" represents scheduled human-intervention time ( 7 a.m.) for the cows milked by the robot to ensure that all cows get milked.

The 5 a.m. average was lower than the 6 a.m. to 7 p.m. and the 10 p.m. averages. The 6 a.m. observation was lower than the 8 a.m. and 6 p.m. averages. The 7 a.m. average was less than 8 a.m. and greater than the 11 p.m. average. Observations from 8 a.m. to 7 p.m. were greater than the 11 p.m. average. These results show that activity in the robot holding area increased after the 7 a.m. human-intervention. The increase observed at 7 a.m. was assumed to be caused by variability of actual vs. scheduled human-intervention times.

The average number of cows in the robot holding area was greatest at 8 a.m. to 11 a.m. (four to five cows), and again at 2 p.m. to 7 p.m. (three to four cows). The average number of cows waiting in the robot holding area was less than two from 8 p.m. to 6 a.m. Activity in the robot holding area increased after human-intervention time and remained high until these cows went through the robot and increased again later in the day as cows were waiting to be milked a second time. Had there been closer to the recommended 60 cows for the robot system, presence of cows in the holding area may have had a different or more pronounced distribution pattern.

Variability in the number of cows in the robot holding area increased during daytime hours and was highest from 8 to 11 a.m. and 3 to 5 p.m. This increased variation may have been caused by differences in humanintervention times or cows may have been waiting to use the robot, not for milking, but to gain access to the feed bunk, as suggested by earlier research (Wendl et al., 2000; Morita et al., 2000).

\section{Milk Yield Comparisons Between Milking Systems}

Daily average milk yields from July 9 to August 16, 2001, were analyzed to examine the effects of milking system (and frequency of milking), parity, DIM, and ambient temperature on milk yield. The parlor side had 84 different cows and the robot side had 44 different cows during this 39-d period. Mean Start-DIM, defined as the DIM for a cow at the beginning of the cow's respective observation period, were similar between robot and parlor groups and averaged $221.9 \pm 7.9$ DIM, indicating that most cows were in mid to late lactation during the summer observations. However, cows in the

Table 1. Mean values for parity, start-DIM, milking frequency, and milk yield ( \pm SE) by management group for data collected during a 39-d summer period.

\begin{tabular}{lrl}
\hline & \multicolumn{1}{l}{ Parlor } & \multicolumn{1}{l}{ Robot } \\
\hline Number of different cows & \multicolumn{1}{l}{ 84 } & \multicolumn{1}{l}{44} \\
Parity & $2.4 \pm 0.1^{\mathrm{a}}$ & $1.6 \pm 0.1^{\mathrm{b}}$ \\
Start-DIM $^{1}$ & $222.7 \pm 10.1^{\mathrm{a}}$ & $220.4 \pm 12.6^{\mathrm{a}}$ \\
Milking frequency $^{\text {Milk yield (lb) }}{ }^{2}$ & $2.0 \pm 0.0^{\mathrm{b}}$ & $2.4 \pm 0.02^{\mathrm{a}}$ \\
\hline
\end{tabular}

\footnotetext{
${ }^{\mathrm{a}, \mathrm{b}}$ Means within row with different subscript differ $(P<0.05)$

${ }^{1}$ Start-DIM refers to DIM for a cow at the beginning of the cow's respective observation period.

${ }^{2} \mathrm{~kg}=\mathrm{lb} / 2.2$
} 


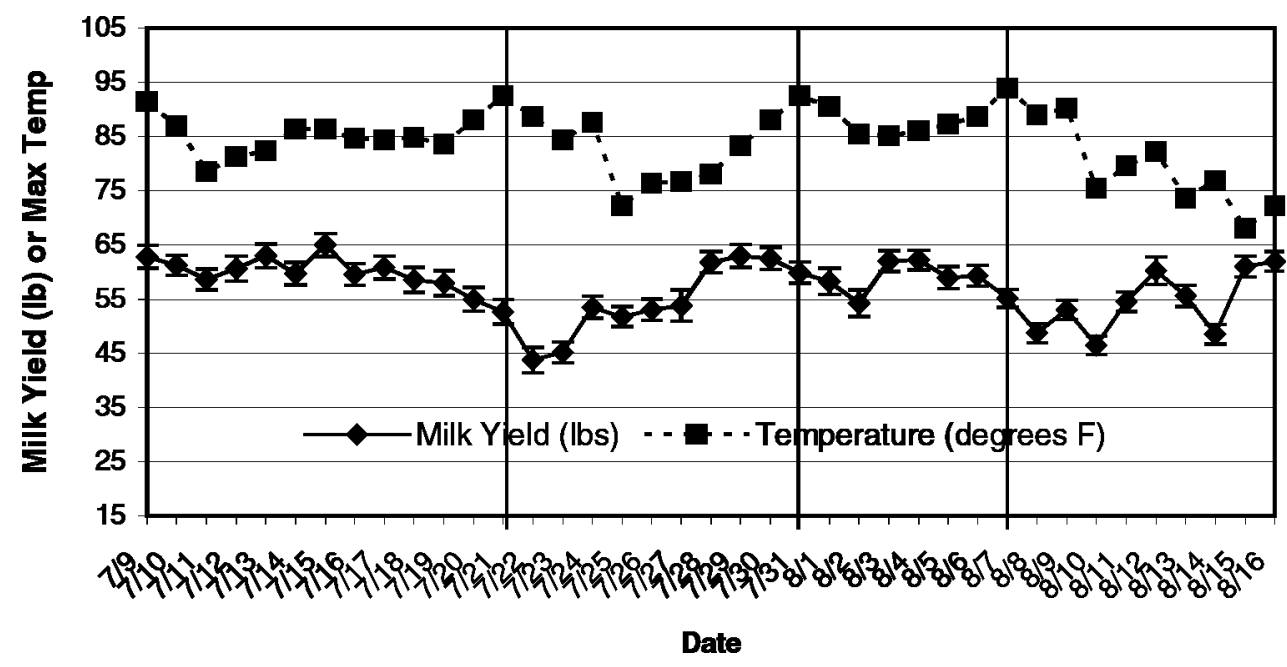

Figure 3. Daily mean milk yield $( \pm$ S.E. $)$ and maximum temperature $\left({ }^{\circ} \mathrm{F}\right)$ for July 9 to August $16,2001 .\left({ }^{\circ} \mathrm{C}=\left({ }^{\circ} \mathrm{F}-32\right) \times 5 / 9\right)$. Vertical lines represent high maximum temperatures on $7 / 9,7 / 21,7 / 31$, and 8/7.

robot system had lower parity (1.6 vs. $2.4 \pm 0.1$ ), higher milking frequency $(2.4 \pm 0.02$ vs. $2.0 \pm 0.0)$, and slightly higher milk production ( 58.1 vs. $56.7 \pm 0.5 \mathrm{lb}$, or 26.4 vs. $25.8 \pm 0.2 \mathrm{~kg})$ than parlor cows $(P<0.05$; Table 1$)$. Lower average parity of cows in the robot group was partially the result of the animal selection process, where cows with uneven udders were assigned to the parlor side to avoid robot unit attachment problems. The lower average parity of cows in the robot management group implies a higher percentage of cows in the robot management group were parity one animals. This would partially explain why milk yield for robot cows was only $1.4 \mathrm{lb}(0.6 \mathrm{~kg})$ higher than for the parlor group even though milking frequency was higher.

Mean maximum temperature ranged from 67.7 to $94.0^{\circ} \mathrm{F}\left(19.8\right.$ to $\left.34.4^{\circ} \mathrm{C}\right)$ with a mean of $83.6 \pm 0.1^{\circ} \mathrm{F}$ $\left(28.7 \pm 0.1^{\circ} \mathrm{C}\right)$. Vertical lines in Figure 3 represent high maximum temperatures on $7 / 9,7 / 21,7 / 31$, and $8 / 7$. Overall, mean milk yields tended to be higher when daily maximum temperatures were lower. Daily mean milk yield ranged from approximately $65 \mathrm{lb}$ on 7/15 to $44 \mathrm{lb}$ on $7 / 22$ (29.5 to $20 \mathrm{~kg}$; Figure 3). Visual inspection of this graph shows a trend for milk yield to drop following hot days. To quantify the effect of high temperature and to determine the effect of the automatic milking system on milk yield, we summarized observations by milking system and developed a milk-yield model to estimate the effects of different variables thought to be related to milk production.

\section{Milk-Yield Model}

Among significant variables, milking frequency accounted for more variation in milk yield $(F$-value $=$
454.3; Table 2), and parity accounted for the least variation $(F$-value $=6.0)$. For the temperature measures, maximum temperature one day previous best explained the variation in milk yield $(F$-value $=37.4)$ with maximum temperature $2 \mathrm{~d}$ previous $(F$-value $=35.4)$ and observation day maximum temperature $(F$-value $=$ 22.8) following. Maximum temperature $3 \mathrm{~d}$ previous added no further information about milk yield. The temperature regression estimates indicate that a $10^{\circ} \mathrm{F}$ $\left(6.1^{\circ} \mathrm{C}\right)$ temperature difference $1 \mathrm{~d}$ previous would cause a $2.5-\mathrm{lb}(1.1 \mathrm{~kg})$ drop in yield after accounting for temperature difference on observation day and $2 \mathrm{~d}$ previous. Temperature effects on $2 \mathrm{~d}$ previous were similar to one day previous. The AR(1) and residual covariance parameter estimates for the model were 0.70 and 238.53 , respectively. The $R^{2}$ value for the model was 0.35 .

Milking frequency was a significant predictor of milk yield. The increase in milk yield estimated by the milkyield model, due to the increased milking frequency of the robot milking system, was approximately $22 \mathrm{lbs}$ (10 $\mathrm{kg}$ ) from $1 \times$ to $2 \times, 14 \mathrm{lb}(6.4 \mathrm{~kg})$ from $2 \times$ to $3 \times$, and 7 $\mathrm{lb}(3.2 \mathrm{~kg})$ from $3 \times$ to $4 \times$. Past research shows increased milk yield by increasing milking frequency to three times a day (Barnes et al., 1990; Speicher et al., 1994; Erdman and Varner, 1995). Erdman and Varner (1995) showed with conventional milking systems average milk production for cows milked $1 \times$ per day produced $13.6 \mathrm{lb}(6.2 \mathrm{~kg})$ less than if they were milked $2 \times$, and increased by 7.7 or $10.8 \mathrm{lb}(3.5$ or $4.9 \mathrm{~kg})$ if they were milked $3 \times$ or $4 \times$ per day, respectively. No attempt was made to determine the time between milkings for the data in the current study. The possibility that cows in the robot pen may have been milked a different number 
Table 2. Significant effects, number of cow-day observations, estimates ( \pm S.E), and F-values of regression model for milk yields collected during one 39-d summer period.



of times or at uneven milking intervals on different days may influence the estimated differences for times milked.

Because the average DIM of the parlor cows and robot cows were not significantly different, it appears that the increased milking frequency by the robot had the greatest influence on the milk yield differences seen. This supports the idea that an automatic milking system can be used to increase milking frequency and daily milk yields. These data also showed that although average milking frequency was increased by $0.4 \times(2.0 \times$ to $2.4 \times$ ), the increase in production was not $40 \%$ of the expected difference in production from $2 \times$ to $3 \times$. This can be partially attributed to the higher percentage of parity one cows, which can be expected to have lower daily milk yields.

The model showed the maximum temperature one day before the milk yield observation had more impact on milk yield than the temperature on the day of or 2 $\mathrm{d}$ before observation day. This result was in agreement with previous research (Maust et al., 1972; Ravagnolo and Misztal, 2000). Cows exposed to high temperatures during summer weather conditions experienced a decrease in milk production (Linvill and Pardue, 1992; Armstrong, 1994). The main reason for decreased production may be associated with a decrease in DMI caused by high temperatures. Feed intakes were not measured and could not be included in the model.

\section{CONCLUSIONS}

Increased cow activity at the feed bunk following scheduled milking times for cows milked in the conventional parlor affirms the recommendation that cows have access to feed after milking. Human intervention seemed to initiate a higher level of robot use, which lasted throughout most of the day. A consistent flow of animals to the feed bunk is different from the slug effect of cows accessing the feed bunk with a conventional parlor system, suggesting that feed bunk requirements for cows milked with a robotic system may be less than the usual 24 in $(0.61 \mathrm{~m})$ per cow. Also, different animal handling systems might need to be designed to select, restrain and treat animals in an automatic milking system environment. Feed bunk activity was lowest during late evening and early morning for cows in both systems suggesting that cows prefer to eat during the day and rest and ruminate during dark hours. Because human intervention increased milking and feeding activity for cows milked with a robot, studying effects on milking frequency, feeding activity, and milk production of additional human intervention during the night would be of interest.

Although the robot management group contained fewer than the recommended 60 cows per robot, it achieved an average of only 2.4 milking per cow per day. This could have been caused by one of the following: 1) cows were conditioned to $2 \times$ milking before entering 
this pen; 2) cows were in the later part of their lactation and did not have sufficient udder pressure or desire to eat as early lactation cows would have; or 3) the low stocking rate could have reduced their natural herding behavior. Milking frequency best explained variation in milk yield and automatic milking systems may effectively increase daily milk yield by increasing milking frequency. Although milking frequency was increased by $0.4 \times(2.0 \times$ to $2.4 \times)$ for robot-milked cows, the increase in average milk yield was not $40 \%$ of the expected difference in production from $2 \times$ to $3 \times$, likely because of a higher percentage of first parity cows in the robot group. Finally, maximum daily temperature from the observation day and from 1 and $2 \mathrm{~d}$ previous were the best temperature measures to predict the effects of hot weather on milk yield.

Future research should consider the effects of other management practices, DMI, and milking interval lengths on milk yield and implications of animal movement on animal handling systems for automatic milking systems.

\section{ACKNOWLEDGMENTS}

The authors would like to thank the employees of the Blaine Dairy, Arlington research facility, for their assistance in switching tapes, Tom Tabone for his SAS programming assistance, Misty Davis for her assistance in gathering the milk yield data and Randy Shaver for his assistance. Funding for this research and publication from the USDA Cooperative State Research, Education and Extension Service (CSREES) project WIS01892.

\section{REFERENCES}

Armstrong, D. V. 1994. Heat stress interaction with shade and cooling. J. Dairy Sci. 77:2044-2050.

Barnes, M. A., R. E. Pearson, and A. J. Lukes-Wilson. 1990. Effects of milking frequency and selection for milk yield on productive efficiency of Holstein cows. J. Dairy Sci. 73:1603-1611.

Erdman, R. A. and M. Varner. 1995. Fixed yield responses to increased milking frequency. J. Dairy Sci. 78:1199-1203.

Linvill, D. E., and F. E. Pardue. 1992. Heat stress and milk production in the South Carolina coastal plains. J. Dairy Sci. 75:2598-2604.

Littell, R. C., P. R. Henry, and C. B. Ammerman. 1998. Statistical analysis of repeated measures data using SAS procedures. J. Anim. Sci. 76:1216-1231.

Maust, L. E., R. E. McDowell, and N. W. Hooven. 1972. Effect of summer weather on performance of Holstein cows in three stages of lactation. J. Dairy Sci. 55:1133-1139.

Morita, S., E. Nirasawa, S. Sugita, S. Hoshiba, M. Tokida, H. Hirayama, and K. Uetake. 2000. Cow behavior and working time of a stockperson in a free-stall barn with an automatic milking-feeding system. Page 188 in Robotic Milking. Proceedings of the International Symposium. H. Hogeveen and A. Meijering, ed., Wageningen Pers, Wageningen, The Netherlands.

O'Connell, J. M., W. J. Meaney, and P. S. Giller. 1993. Behavioural studies - their role in improving housing facilities for overwintering dairy cows. Pages 298-305 in Livestock Environment IV, 4th International Symposium. Univ. Warwick, Conventry, England.

Olofsson, J., G. Pettersson, and H. Wiktorsson. 2000. Feeding behaviour in an automatic milking system. Page 189 in Robotic Milking. Proceedings of the International Symposium. H. Hogeveen and A. Meijering, ed., Wageningen Pers, Wageningen, The Netherlands.

Ravagnolo, O., and I. Misztal. 2000. Genetic component of heat stress in dairy cattle, parameter estimation. J. Dairy Sci. 83:2126-2130.

SAS. 1999. 8.0. http://shelf.doit.wisc.edu/SasOnlineDocs/onldoc.htm.

Speicher, J. A., H. A. Tucker, R. W. Ashley, E. P. Stanisiewski, J. F. Boucher, and C. J. Sniffen. 1994. Production responses of cows to recombinantly derived bovine somatotropin and to frequency of milking. J. Dairy Sci. 77:2509-2517.

Wagner-Storch, A. M., R. W. Palmer, and D. W. Kammel. 2002. Factors affecting cow preference for freestall bases in pens with different stocking densities. M.S. Thesis, Univ. Wisconsin, Madison, WI.

Wendl, G., J. Harms, and H. Schon. 2000. Analysis of milking behaviour on automatic milking. Pages $143-151$ in Robotic Milking. Proceedings of the International Symposium. H. Hogeveen and A. Meijering, ed., Wageningen Pers, Wageningen, The Netherlands.

West, J. W. 1994. Interactions of energy and bovine somatotropin with heat stress. J. Dairy Sci. 77:2091-2102. 